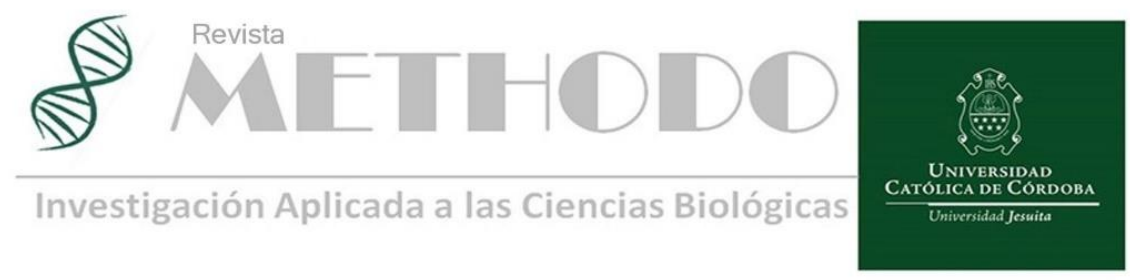

SEMBLANZA Rev. Methodo 2020;5(3):117-118 https://doi.org/10.22529/me.2020.5(3)08

Recibido 01 Ene. 2019 | Publicado 03 Jul. 2020

\title{
Prof. Dr. Walter A. González Becerra (1933 - 2009)
}

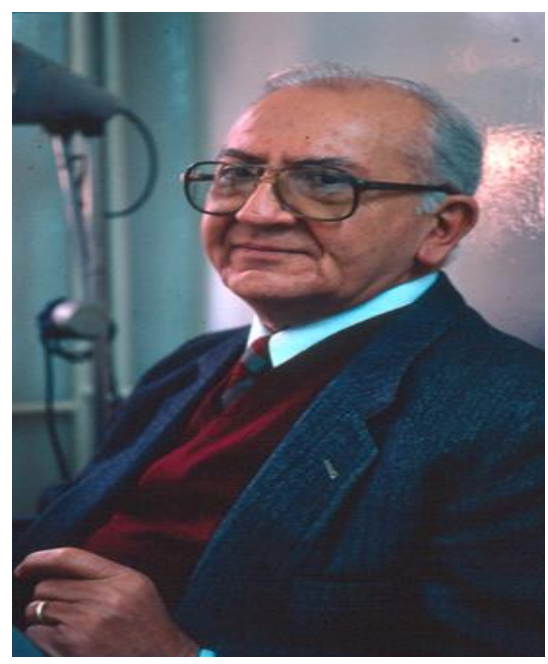

Figura 1. Prof. Dr. Walter A. González Becerra

\section{Homenaje Maestro de la Dermatología Argentina al profesor Dr. Walter A. González Becerra 8 de junio 2007}

Me solicitaron que hiciera la semblanza, quiero contar que acepte gustosa ... aunque no me fue tarea fácil. Hablar de mi papá, en unos minutos reconocer la trayectoria de una vida ejemplar. El profesor Dr. Walter A González Becerra, nació un 19 de enero de 1933, en la ciudad de San Juan, en el barrio del Carrascal. Desarrollo una infancia feliz entre sus familiares, fue a la escuela Sarmiento y la secundaria Colegio Nacional Monseñor Pablo Cabrera.
Corría el año 1951 cuando deja su casa natal, para trasladarse a la Docta, para estudiar medicina en la Facultad de Ciencias Médicas de la Universidad Nacional de Córdoba, vivía en una residencia universitaria en pleno barrio clínicas, épocas difíciles para la vida universitaria. Estaban en la lucha por la enseñanza libre, durante tres años no se tomaron exámenes en la universidad.

Antes de terminar la carrera por el año 60 ya mostró su inclinación por la especialidad, fue practicante mayor de la Cátedra de Dermatología en el Hospital de Nacional de Clínicas.

Finalmente, para diciembre de 1962 se recibió de médico, por supuesto continuo con la especialidad de dermatología de ahí en mas no se alejó de sus maestros algunos de ellos: Dr. Arguello Pitt, Dr. Carlos Consigli, también conoció a quien fue su colega, amigo, el hermano que uno elige Dr. Edmundo Chappuis.

En 1964 se casó y se radicaron en Córdoba, más allá de la alegría y esperanza, me imagino los miedos y desafíos, años siguientes nacimos sus tres hijas y así quedaría configurada nuestra familia. Época muy intensa de muchas horas dedicadas al trabajo, al estudio, hasta los fines de semana tenía consultorio, combinar el trabajo con la familia no resulto fácil, el rol de proveedor se tornó mas y más exigente. Como también las obligaciones de mediador y pacificador. Se convirtió en el ancla que mantiene a salvo todo lo que la familia representa.

Recuerdo esa época de reuniones: de la catedra, del hospital, de la dermatología, de la leprología simplemente como momentos de intenso trabajo tiempo de organizar cursos, seminarios, congresos.

Revista Methodo: Investigación Aplicada a las Ciencias Biológicas. Universidad Católica de Córdoba. Jacinto Ríos 571 Bo Gral. Paz. X5004FXS. Córdoba. Argentina. Tel.: (54) 351 4517299 / Correo: methodo@ucc.edu.ar / Web: methodo.ucc.edu.ar | SEMBLANZA Rev. Methodo 2020;5(3):117-118. 
Ocupando todos los cargos de las sociedades científicas.

Desde 1971, también comenzó a ser docente de la Catedra de Clínica Dermatológica de la Universidad Católica de Córdoba. Primero como docente asistente, después jefe de trabajos prácticos, profesor adjunto y a partir de 1988 fue profesor titular.

Entonces tuve la dicha, la oportunidad, el gozo de tenerlo como profesor. Muchos saben lo que significa la universidad como mi segundo hogar, donde también él me acompañó.

Continuo como profesor hasta 1998 que se retiró y en esa ocasión escribió:

"Detrás de cada final, hay un comienzo.

Detrás de cada logro hay un desafío.

Seguí, aunque todos esperen que te detengas.

Mañana será un día nuevo para reiniciar la tarea.

Y siempre mientras estés vivo, agradeciendo al Señor sentirte vivo ...”

Continuo como profesor invitado hasta noviembre del año 2005 que lo distinguieron como profesor emérito de la Universidad Católica de Córdoba, para ser hoy maestro de la dermatología Argentina. Fui creciendo conociéndole, con su carácter firme, sereno, dispuesto a la escucha, al diálogo sincero. Al consejo oportuno y al perdón.

Quiero decir hoy también gracias porque cuando las cosas no resultaban como las esperaba sabía que podíamos contar con tu palabra de aliento. Me ha guiado suavemente, pero con firmeza a lo largo de la vida.

Con los colegas compartimos momentos inolvidables, lleno de respeto y de un afecto que sin dejar lo científico alentó al calor de la amistad, como patrimonio de la generosidad.

Cuando cumplió los 70 años nos escribió en una tarjeta.
“Gracias Señor por permitirnos reunir para recordar y festejar.

Agradecemos a Dios nuestro Señor por lo que nos entregó de su infinita bondad.

Le doy gracias porque me regalo la maravillosa compañía de mi esposa, que lleno de amor, armonía y felicidad toda mi vida.

Luego me distinguió, premiándome al darme tres hijas y mi nieta que completaron la verdadera razón de nuestra existencia.

Gracias a mis amigos y familiares por su generosa tolerancia y su apoyo invalorables.

Agradezco estar convencido, que lo mas grande que un hombre puede hacer por sus hijos es amar a la madre de sus hijos."

Creo que la familia, la dermatología, los amigos y la Fe, fueron los pilares de su vida. Doy gracias a Dios de compartirlos.

Antes de finalizar quiero dar gracias:

Al Dr. Alejandro Ruiz Lascano y al Dr. Carlos Consigli, que como delegado regional y presidente de la sección Córdoba de la Sad y lo propusieron para ser maestro.

A las autoridades de la Sociedad Argentina de Dermatología que lo distinguieron, a los dermatólogos que hoy nos acompañan, a los familiares y amigos que están presentes; y a los que desde mas allá nos acompañan también.

Gracias a todos los presentes.

Dra. María Eleonora González.

(Universidad Católica de Córdoba. Facultad de Ciencias de la Salud. Docente de Dermatología)

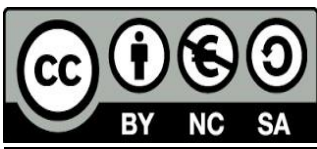

